\title{
Reaction-Driven Restructuring of Rh-Pd and Pt-Pd Core-shell Nanoparticles
}

\author{
Feng Tao ${ }^{1,2}$, Michael E. Grass ${ }^{1,2}$, Yawen Zhang ${ }^{1,2,5}$, Derek R. Butcher ${ }^{1,2}$, James R. Renzas ${ }^{1,2}$, , \\ Zhi Liu ${ }^{3}$, Jen Y. Chung ${ }^{3}$, Bongjin S. Mun ${ }^{3}$, Miquel Salmeron ${ }^{1,4}$, Gabor A. Somorjai ${ }^{1,5 *}$ \\ Lawrence Berkeley National Laboratory, Berkeley, CA $94720^{1}$ \\ Department of Chemistry, University of California, Berkeley CA $94720^{2}$ \\ Advanced Light Source, Lawrence Berkeley National Laboratory, Berkeley CA $94720^{3}$ \\ Department of Materials Science and Engineering, University of California, Berkeley CA $94720^{4}$ \\ College of Chemistry and Molecular Engineering, Peking University, Beijing 100871, China ${ }^{5}$
}

The structure and composition of core-shell $R h_{0.5} P d_{0.5}$ and $P t_{0.5} P d_{0.5}$ nanoparticle catalysts were studied in situ, during oxidizing, reducing, and catalytic reactions involving $\mathrm{NO}, \mathrm{O}_{2}, \mathrm{CO}$, and $\mathrm{H}_{2}$ using $\mathrm{X}$-ray photoelectron spectroscopy in the Torr pressure range. The $R h_{0.5} P d_{0.5}$ nanoparticles undergo dramatic and reversible changes in composition and chemical state in response to oxidizing or reducing conditions. Under oxidizing conditions the Rh atoms segregate to the shell region while in reducing atmospheres the Pd atoms diffuse to the shell region. In contrast no significant segregation of Pd or Pt atoms was found in $P t_{0.5} P d_{0.5}$ nanoparticles. The distinct behavior in restructuring and chemical response of $R h_{0.5} P d_{0.5}$ and $P t_{0.5} P d_{0.5}$ nanoparticle catalysts under the same reaction conditions illustrates the flexibility and tunability of the structure of bimetallic nanoparticle catalysts during catalytic reactions.

*Corresponding authors. Email: somorjai@ berkeley.edu; mbsalmeron@lbl.gov 
The development of bimetallic nanoparticles with controlled size, composition and structure opens enormous possibilities for engineering new catalysts with enhanced activity and selectivity. Important technological areas, including catalytic reforming $(1,2)$, pollution control (1), alcohol oxidation (3), and electrocatalysis in fuel cells (4) are based on bimetallic catalytic systems $(5,6)$. While it is known that the structure and composition of the surface of materials can be modified in response to changing reaction conditions $(1,7,8)$, when the size of the material is in the nanometer scale, the changes can be very dramatic as the distinction between surface and bulk regions fades away. In the case of nanoparticle catalysts this can lead to an entirely new material with distinct chemical functions.

In this report we demonstrate that bimetallic nanoparticle catalysts can undergo profound structural and chemical changes in response to reactive environments at ambient pressures. This has been possible by the use of an ambient pressure XPS (APXPS) apparatus $(9,10)$, that can be used to obtain X-ray photoelectron spectra of materials under relatively high gas pressures, currently up to 5 to 10 Torr. With it we could study in-situ the structure and composition of core-shell $\mathrm{Rh}_{0.5} \mathrm{Pd}_{0.5}$ and $\mathrm{Pt}_{0.5} \mathrm{Pd}_{0.5}$ bimetallic nanoparticles during catalytic reactions in different gas environments. The composition and distribution of the constituent elements within the shell of $\mathrm{Rh}_{0.5} \mathrm{Pd}_{0.5}$ nanoparticles was found to change dramatically in response to changes in reactant gas composition, a result that demonstrates the unique structural flexibility of nanoparticles and the interplay of structure and reactivity.

$\mathrm{Rh}_{0.5} \mathrm{Pd}_{0.5}$ and $\mathrm{Pt}_{0.5} \mathrm{Pd}_{0.5}$ bimetallic nanoparticles with diameters of $15 \pm 2 \mathrm{~nm}$ were synthesized using colloidal chemistry methods (see supporting on-line material) and characterized by TEM and XRD. Nanoparticles $\mathrm{Rh}_{0.5} \mathrm{Pd}_{0.5}$ or $\mathrm{Pt}_{0.5} \mathrm{Pd}_{0.5}$ were deposited on silicon wafers to form model catalysts for XPS studies. The spectra were obtained using X-ray 
photon energies of $645 \mathrm{eV}$ and $850 \mathrm{eV}$ at the Advanced Light Source, the Berkeley Synchrotron Facility, and in vacuum using $\mathrm{Al} \mathrm{K \alpha} \mathrm{X}$-rays at $1486.6 \mathrm{eV}$ in a laboratory Phi 550 instrument. The mean free paths (MFPs) of Rh3d and Pd3d photoelectrons excited at these three X-ray energies are approximately $0.7,1.0$, and $1.6 \mathrm{~nm}$, respectively (11). The structure of the $\mathrm{Pt}_{0.5} \mathrm{Pd}_{0.5}$ nanoparticles was studied at photon energies of 630,880 , and $1486.6 \mathrm{eV}$ for Pd3d, and 350, 630, and $1486.6 \mathrm{eV}$ for Pt4f. The MFPs of the generated Pd3d and Pt4f photoelectrons were also $0.7,1.0,1.6 \mathrm{~nm}$, respectively (11).

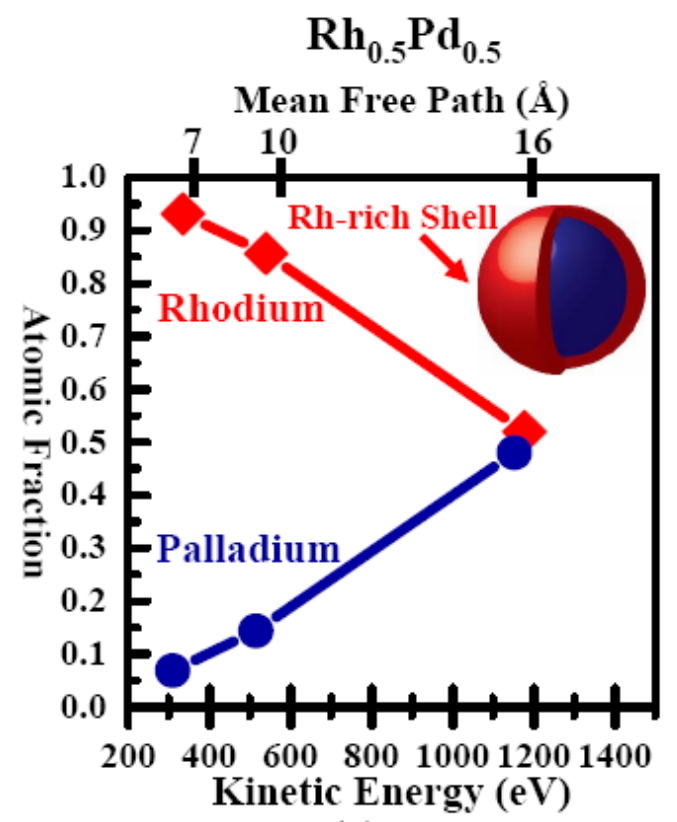

(a)

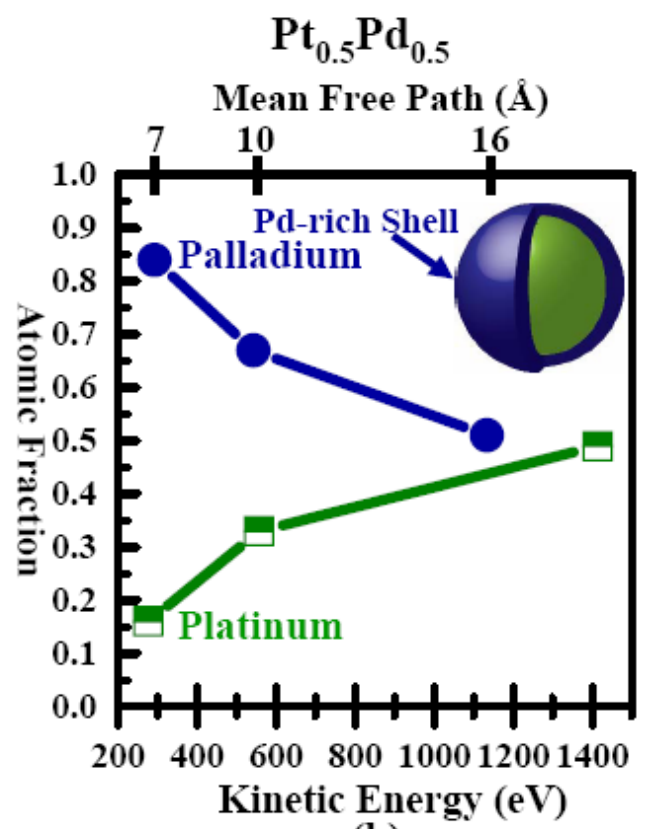

(b)

Fig. 1. (a) Dependence of rhodium and palladium atomic fractions of as-synthesized $\mathrm{Rh}_{0.5} \mathrm{Pd}_{0.5}$ nanoparticles measured at $25^{\circ} \mathrm{C}$ in UHV as a function of photoelectron kinetic energy and mean free path. Detected photoelectrons with a kinetic energy of $\sim 1152 \mathrm{eV}$ originate from both the shell, intermediate layer and central core of the $\mathrm{Rh}_{0.5} \mathrm{Pd}_{0.5}$ nanoparticles. The signal of photoelectrons with kinetic energy of $\sim 335$ and $\sim 540 \mathrm{eV}$ is mainly contributed from the atoms in surface layers because of the shorter mean free path of these photoelectrons. (b) Dependence of palladium and platinum atomic fractions of the as-synthesized $\mathrm{Pt}_{0.5} \mathrm{Pd}_{0.5}$ measured in $\mathrm{UHV}$ at $25^{\circ} \mathrm{C}$ as a function of the kinetic energy and mean free path of the excited photoelectrons. Schematics showing the core-shell structures of the $\mathrm{Rh}_{0.5} \mathrm{Pd}_{0.5}$ nanoparticle and $\mathrm{Pt}_{0.5} \mathrm{Pd}_{0.5}$ nanoparticle are included (These schematics do not represent the shape of the nanoparticles). 
Before use in catalytic reactions, the as-synthesized $\mathrm{Rh}_{0.5} \mathrm{Pd}_{0.5}$ nanoparticles were found to be significantly Rh-rich in the surface layers, as shown in Fig.1a. At the lowest photon energy $(\mathrm{h} v=645 \mathrm{eV}, \mathrm{KE}=\sim 335 \mathrm{eV})$, corresponding to a mean free path of $0.7 \mathrm{~nm}$, the measured atomic fraction of $\mathrm{Rh}$ is 0.93 . The determination of atomic fractions of rhodium and palladium is described in the supporting on-line material. The average $\mathrm{Rh}$ atomic fraction decreases to 0.86 and 0.52 at depths corresponding to the mean free paths of $1.0 \mathrm{~nm}$ (hv $=850$ $\mathrm{eV}, \mathrm{KE}=\sim 540 \mathrm{eV})$ and $1.6 \mathrm{~nm}(\mathrm{~h} v=1486.6 \mathrm{eV}, \mathrm{KE}=\sim 1180 \mathrm{eV})$, respectively. In the following we use the name 'shell' to refer to the 3 to 4 atomic layers within $0.7 \mathrm{~nm}$ of the surface. The section between 0.7 and $1.6 \mathrm{~nm}$ will be referred to as the 'intermediate layer' and from $1.6 \mathrm{~nm}$ to the centre of a nanoparticle as the 'central core'. The volume of material analyzed from the surface to the boundary of these three regions is respectively $25 \%, 35 \%$ and $51 \%$.

$\mathrm{Pt}_{0.5} \mathrm{Pd}_{0.5}$ nanoparticles have a similar core-shell structure but the shell is now significantly Pd-rich (Fig. 1b). The observed atomic fraction of Pd in these nanoparticles is $0.84,0.67$, and 0.52 within the MFP distances of $0.7,1.0$, and $1.6 \mathrm{~nm}$, respectively.

After the initial characterization, we measured the changes in surface composition and chemical state of the $\mathrm{Rh}_{0.5} \mathrm{Pd}_{0.5}$ nanoparticles under oxidizing (100 mTorr $\mathrm{NO}$ or $\mathrm{O}_{2}$ ), catalytic (100 mTorr NO and 100 mTorr $\mathrm{CO}$ reacting to produce $\mathrm{N}_{2}$ and $\mathrm{CO}_{2}$ ), and reducing (100 mTorr $\mathrm{CO}$ or $\mathrm{H}_{2}$ ) conditions using APXPS. The atomic fractions presented in Fig. 2 were obtained with an X-ray energy of $645 \mathrm{eV}$ and thus represent the changes in composition in the $0.7 \mathrm{~nm}$ shell. The top panel of Fig. 2 shows a significant oscillation of the relative atomic fractions as the gas environment changes from oxidizing to catalytic at $300^{\circ} \mathrm{C}$. After oxidation by 100 mTorr NO, the rhodium in the shell is almost completely oxidized with $\sim 94 \%$ of the 
rhodium in oxide form. When 100 mTorr CO was added to the 100 mTorr NO to produce $\mathrm{CO}_{2}$ and $\mathrm{N}_{2}$ (catalytic conditions), the total rhodium atomic fraction in the shell decreased from 0.92 to 0.46 and that of palladium increased from 0.08 to 0.54 (reaction 2 in top panel of Fig. 2). This indicates a drastic restructuring of the shell and core of the nanoparticle, where $\mathrm{Pd}$ migrates to the shell and $\mathrm{Rh}$ migrates to the core. The production of $\mathrm{CO}_{2}$ and $\mathrm{N}_{2}$ formed in the reaction was measured by sampling gas into a mass spectrometer located in a separate UHV chamber, indicating that the nanoparticles are active for $\mathrm{CO}$ and $\mathrm{NO}$ catalytic conversion. The $\sim 1.0 \mathrm{eV}$ downshift in binding energy of the Rh3d core-level indicates the reduction of $\mathrm{RhO}_{\mathrm{y}}$ to metal $\mathrm{Rh}^{0}$. The rhodium that remains in the shell is $\sim 76 \%$ metallic during the catalytic reaction (reaction 2), in contrast to the $\sim 94 \% \mathrm{RhO}_{\mathrm{y}}$ during the oxidizing reaction. The reduction of $\mathrm{RhO}_{\mathrm{y}}$ to metallic $\mathrm{Rh}$ shows a significant chemical response accompanying the change in atomic distribution.

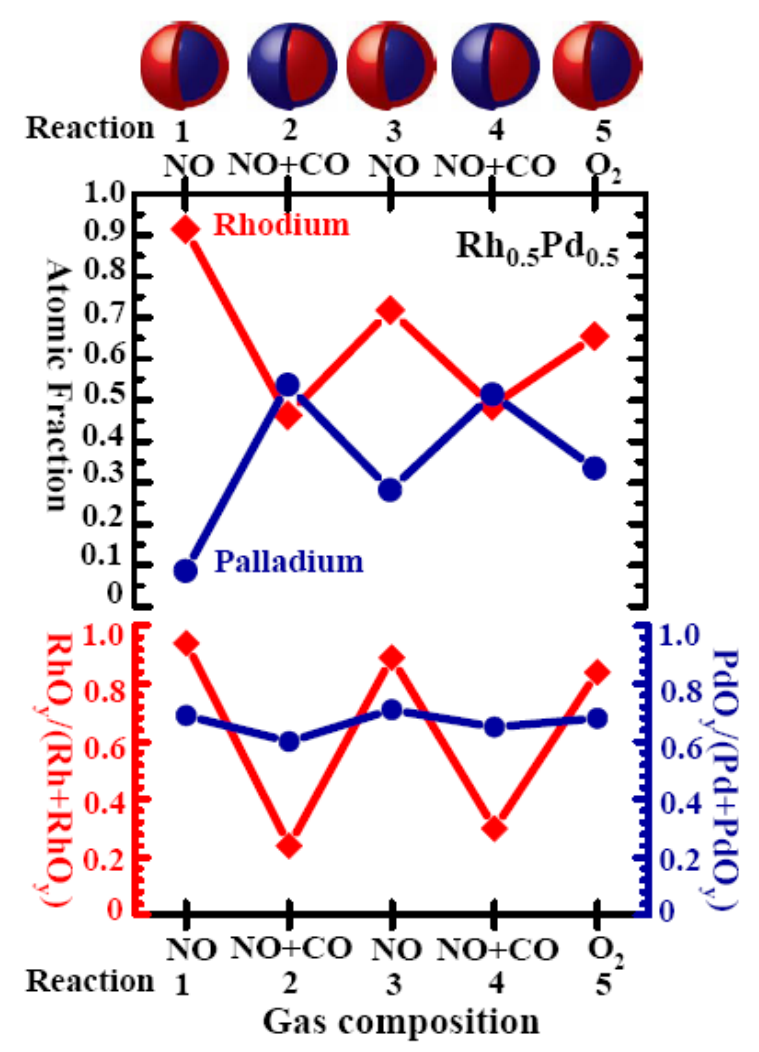


Fig. 2. Top panel: evolution of rhodium $\left(R h^{0}+R h^{2 y+}\right)$ and palladium $\left(\mathrm{Pd}^{0}+\mathrm{Pd}^{2 \mathrm{y}+}\right)$ atomic fractions in the $\mathrm{Rh}_{0.5} \mathrm{Pd}_{0.5}$ nanoparticles at $300^{\circ} \mathrm{C}$ under oxidizing conditions (100 mTorr $\mathrm{NO}$ or $\mathrm{O}_{2}$ ) and catalytic conditions (100 mTorr NO and $100 \mathrm{mTorr} \mathrm{CO}$ ) denoted in the X-axis. Bottom panel: evolution of the fraction of the oxidized Rh (left $y$-axis) and $\mathrm{Pd}$ atoms (right $\mathrm{y}$-axis) in the examined region under the same reaction conditions as the top panel. All atomic fractions in this figure were obtained with an Xray energy of $645 \mathrm{eV}$ for Rh3d and $\mathrm{Pd} 3 \mathrm{~d}$ which generates photoelectrons with a mean free path of $\sim 0.7 \mathrm{~nm}$. Schematic diagrams above the top panel show the reversible segregation of $\mathrm{Rh}$ and $\mathrm{Pd}$ at alternating oxidizing and catalytic conditions.

The observed changes in atomic distribution and chemical state are reversible and depend on the composition of the surrounding reactive gases, as shown in a sequence of five reactions in Fig.2. If $\mathrm{CO}$ is removed while $\mathrm{NO}$ remains in the reactor chamber (reaction 3 in Fig.2), Rh diffuses back to the shell and becomes significantly oxidized. Analysis of the XPS peaks shows that the reconstructed shell contains $\sim 72 \%$ rhodium (top panel of Fig.2), of which $~ 90 \%$ is oxidized (bottom panel. If CO is introduced again, added to the NO gas phase (reaction 4), the spatial distribution and chemical state of the atoms are restored to those during reaction 2. The restructuring of the shell and core of the $\mathrm{Rh}_{0.5} \mathrm{Pd}_{0.5}$ nanoparticles can be repeated several times by changing the gas composition from oxidizing $\left(\mathrm{NO}\right.$ or $\left.\mathrm{O}_{2}\right)$ to reducing $(\mathrm{CO})$ or catalytic $(\mathrm{CO}+\mathrm{NO})$ conditions as shown in Figs. 2 and $\mathrm{S} 3$. If another reducing gas, hydrogen, is used instead (reaction 2 in Fig.S4), the $\mathrm{RhO}_{\mathrm{y}}$ is reduced, with the $\mathrm{Rh}$ atoms migrating back to the core and the Pd atoms to the shell, forming a palladium-rich shell similar to that formed in pure $\mathrm{CO}$ (Fig.S3). Using $\mathrm{Al} \mathrm{K \alpha} \mathrm{X-rays} \mathrm{at} 1486.6 \mathrm{eV}$, the $\mathrm{Rh}$ fraction in the $\mathrm{Rh}_{0.5} \mathrm{Pd}_{0.5}$ nanoparticles measured in $\mathrm{UHV}$ after alternating oxidizing and reducing reactions (Fig.S4) was found to be 0.36 , much lower than the 0.52 value of the assynthesized nanoparticles before reaction also measured in UHV with Al Ka X-rays (Fig. 1a). This difference indicates that the core region (deeper larger than $1.6 \mathrm{~nm}$ ) also participates into the restructuring of the nanoparticles. 
The opposite segregation behavior of $\mathrm{Rh}$ and $\mathrm{Pd}$ under oxidizing and reducing conditions can be explained by considering the surface energy in the metals and in the oxides. The lower surface energy of $\mathrm{Pd}$ relative to $\mathrm{Rh}$ tends to drive $\mathrm{Pd}$ metal atoms to the surface (12-14). The fact that the $\mathrm{Rh}$ oxide is more stable than Pd oxide provides the driving force for the segregation and preferential oxidation of $\mathrm{Rh}$ at the surface (15). When a reducing gas, $\mathrm{CO}$, is added to NO, the oxides are reduced to the metallic state and the oxygen atoms react with adsorbed $\mathrm{CO}$ to form $\mathrm{CO}_{2}$ and desorb. Due to their higher surface free energy, the $\mathrm{Rh}$ atoms migrate to the core, thereby decreasing the atomic fraction of $\mathrm{Rh}$ in the shell during reducing and catalytic conditions.

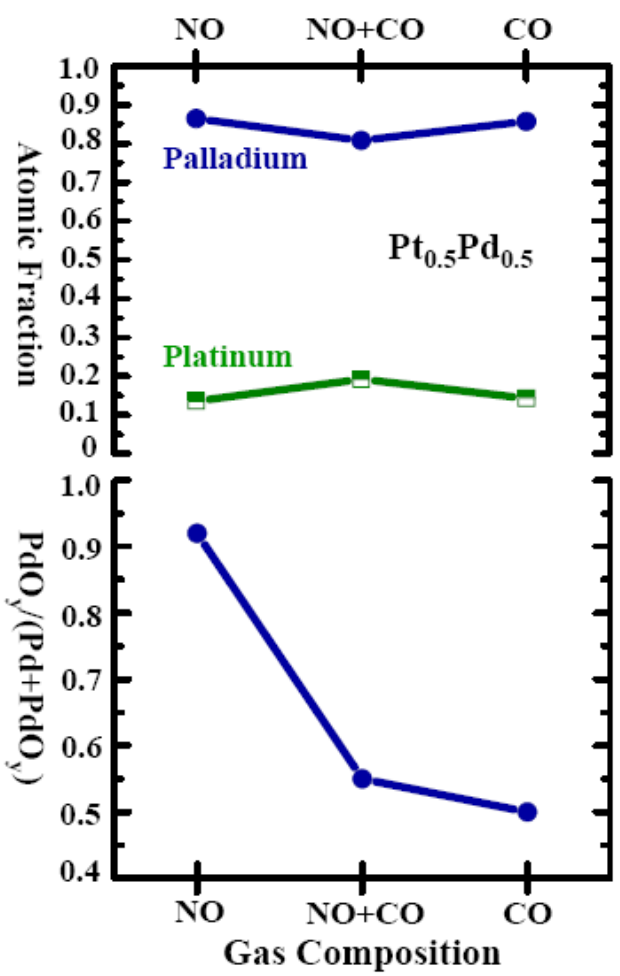

Fig. 3. Top panel: evolution of the palladium and platinum atomic fractions in $\mathrm{Pt}_{0.5} \mathrm{Pd}_{0.5}$ nanoparticles at $300^{\circ} \mathrm{C}$ under oxidizing $(100 \mathrm{mTorr} \mathrm{NO})$, catalytic (100 mTorr NO and 100 mTorr $\mathrm{CO}$ ), and reducing (100 mTorr CO) conditions. The X-axis represents the different gas environments. Bottom panel: evolution of the atomic fraction of the oxidized $\mathrm{Pd}$ atoms in the examined region under the same reaction conditions as the top panel. All atomic fractions were obtained at an X-ray with energy of $350 \mathrm{eV}$ for Pt4f (KE 280 eV) and $630 \mathrm{eV}$ for Pd3d (KE $280 \mathrm{eV}$ ). 
In the $\mathrm{Pt}_{0.5} \mathrm{Pd}_{0.5}$ nanoparticles, synthesized with the same procedure described in the supporting information, the shell region is significantly richer in Pd. Pd has lower surface energy and is a more reactive metal compared to $\mathrm{Pt}(14,15)$. In oxidizing conditions it forms a shell with $92 \% \mathrm{PdO}_{\mathrm{y}}$ without significant segregation of $\mathrm{Pt}$ atoms compared to the assynthesized $\mathrm{Pt}_{0.5} \mathrm{Pd}_{0.5}$ nanoparticles (Figs.3 and $1 \mathrm{~b}$ ). During catalytic reaction and under reducing conditions, the $\mathrm{PdO}_{\mathrm{y}}$ is significantly reduced (bottom panel of Fig.3). There is no obvious segregation under these conditions. Compared to $\mathrm{Rh}_{0.5} \mathrm{Pd}_{0.5}$, however, the $\mathrm{Pt}_{0.5} \mathrm{Pd}_{0.5}$ nanoparticles do not exhibit the strong segregation and reversibility characteristic of the $\mathrm{Rh}_{0.5} \mathrm{Pd}_{0.5}$ nanoparticles as the gas composition changes sequentially from oxidizing, to catalytic and to reducing as shown in the top graph of Fig. 3. Since Pt is much less easily oxidized (15), and has higher surface energy (14), the Pt atoms are not pinned to the surface by the formation of oxide. Thus, there is no significant atomic reorganization in reactive environments.

The restructuring phenomenon observed on the bimetallic nanoparticles induced by changes in reactive gas offers an interesting way of engineering the nanostructure of nanoparticles for catalysis and other applications. One goal could be the synthesis of "smart" catalysts whose structure changes advantageously depending on the reaction environment. In conclusion, by means of ambient pressure XPS we have demonstrated that dramatic restructuring and changes in atomic distribution and chemical state take place in bimetallic nanoparticle catalysts during reactions under Torr pressures of reactant gases which are also reversible. Our results suggest that the combination of a tunable colloid chemistry-based synthesis followed by the controllable engineering of the structure of nanoparticles using 
reactive gases opens a new door for designing new catalysts and shaping catalytic properties of nanomaterials by structural engineering in reactive environment.

\section{References}

1. G. A. Somorjai, Introduction to Surface Chemistry and Catalysis (Wiley VCH, 1999), pp 500-512.

2. G. W. Huber, J. W. Shabaker, J. A. Dumesic, Science 300, 2075-2077 (2003).

3. D. I. Enache, J .K. Edwards, P. Landon, B. Solsona-Espriu, A. F. Carley, A. A. Herzing, M. Watanabe, C. J. Kiely, D. W. Knight, G. J. Hutchings, Science 311, 362-365 (2006).

4. F. Maroun, F. Ozanam, O. M. Magnussen, R. J. Behm, Science 293, 1811-1814 (2001).

5. C. Burda, X. Chen, R. Narayanan, and Mostafa A. El-Sayed, Chem. Rev. 105, 1025-1102 (2005).

6. A. Christensen, P. Stoltze and J. K. Norskov, J. Phys. Cond.. Matter. 7, 1047-1057 (1995).

7. C. T. Campbell, Ann. Rev. Phys. Chem. 41, 775-837 (1990).

8. J. A. Rodriguez, D. W. Goodman, Science 257, 897-903 (1992).

9. D. F. Ogletree, H. Bluhm, G. ebedev, C. S. Fadley, Z. Hussain, M. Salmeron, Review of Scientific Instruments 73, 3872-3877 (2002).

10. M. Salmeron, R. Schloegl, Surface Science Reports 63, 169-199 (2008).

11. C. J. Powell, A. Jablonski, NIST Electron Inelastic-Mean-Free-Path Database 1.1 ed., (National Institute of Standards and Technology, Gaithersburg, MD, 2000).

12. A.V. Ruban, H.L. Skriver, J.K. Norskov, Phys. Rev. B. 59, 15990-16000 (1999).

13. T. Maillet, J. Barbier, P. Gelin, H. Praliaud, D. Duprez, J.l Catal. 202, 367-378 (2001).

14. H. L. Skriver, N. M. Rosengaard, Phys. Rev. B 46, 7157-1768 (1992).

15. M. Salmeron, L. Brewer, G. A. Somorjai, Surface Science 112, 207-228 (1981).

16. This work was supported by the Director, Office of Science, Office of Advanced

Scientific Computing Research, Office of Basic Energy Sciences, Materials Sciences and Engineering, and Chemical Sciences, Geosciences, and Biosciences Division of the U.S. Department of Energy under Contract No. DE-AC02-05CH11231.

Supporting Online Material

www.sciencemag.org

Materials and Methods

Supporting Text

Figs. S1-S4

References 


\section{Supporting On-line Material}

\section{Ambient Pressure XPS (APXPS)}

A photoelectron spectrometer capable of operating under ambient pressures (up to several Torr) was developed at Lawrence Berkeley National Laboratory $(1,2)$. To overcome the short mean free path $(\lambda)$ of the photoelectrons traveling through a gas phase $(\lambda$ is of the order of $\mathrm{mm}$ in the Torr range), the sample is located close to the small aperture of a cone $(\varnothing<0.3 \mathrm{~mm})$ with a distance $<\lambda$ (Fig. S1). This aperture separates the high pressure environment of the reactor from a first pumping stage. This is followed by two other differentially pumped stages with the apertures that separate them located at the focal plane of an electron optics system that focuses the electrons into a hemispherical analyzer located in the final chamber. The instrument takes advantage of the variable energy of synchrotron generated X-rays to obtain non-destructive depth profiles of composition and chemical state near the surface by virtue of the varying mean free paths of electrons inside the material.

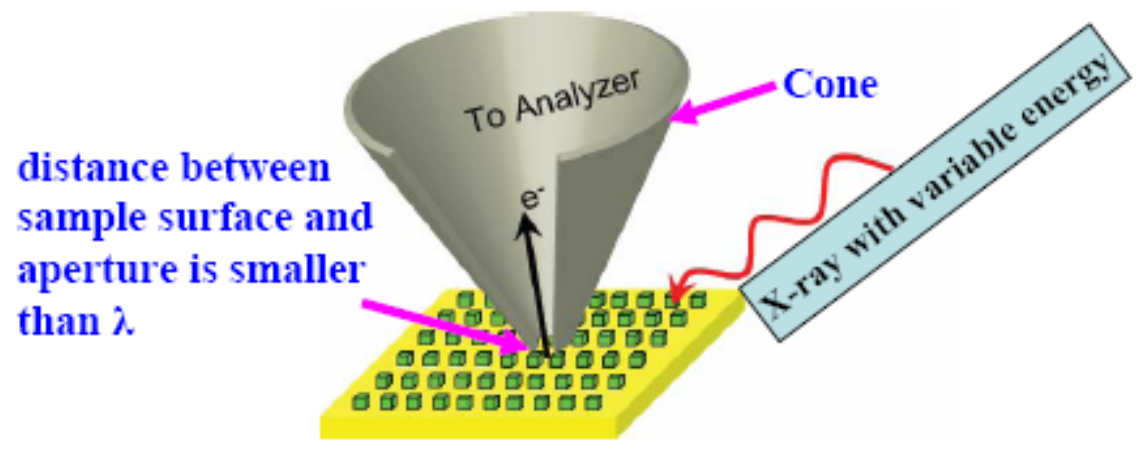

Fig. S1. Schematic showing the configuration of sample and cone.

\section{Synthesis and Preparation of Model Nanoparticle Catalysts}

$\mathrm{Rh}_{0.5} \mathrm{Pd}_{0.5}$ nanoparticles were synthesized with the following procedure: $0.05 \mathrm{mmol}$ $\mathrm{Rh}(\mathrm{acac})_{3}$ and $0.05 \mathrm{mmol} \mathrm{Pd}(\mathrm{acac})_{2}$ and $1 \mathrm{mmol} \mathrm{PVP}$ were added to $20 \mathrm{ml}$ of 1,4-butanediol in a $50 \mathrm{ml}$ three-necked flask at room temperature. The solution was heated to $50{ }^{\circ} \mathrm{C}$ and evacuated at this temperature for $20 \mathrm{~min}$ to remove water and oxygen under magnetic stirring, forming a transparent orange-yellow solution. The flask was then heated to $220{ }^{\circ} \mathrm{C}$, at a rate

of $10{ }^{\circ} \mathrm{C} \mathrm{min}{ }^{-1}$, and maintained at this temperature $\left( \pm 2{ }^{\circ} \mathrm{C}\right)$ for $1.5 \mathrm{~h}$ under Ar gas. When the reaction was complete, an excess of acetone was poured into the solution at room temperature to form a cloudy black suspension. This suspension was separated and the black product was collected by discarding the colorless supernatant. The precipitated $\mathrm{Rh}_{0.5} \mathrm{Pd}_{0.5}$ nanoparticles were washed with acetone and then re-dispersed in ethanol. 

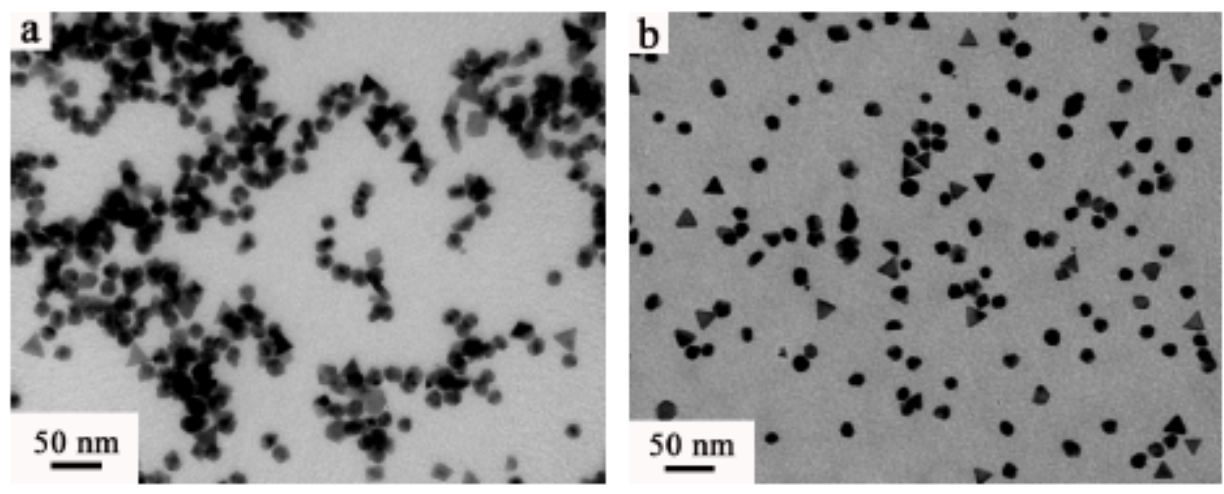

Fig. S2. TEM images of as-synthesized $\mathrm{Rh}_{0.5} \mathrm{Pd}_{0.5}$ (a) and $\mathrm{Pt}_{0.5} \mathrm{Pd}_{0.5}$ (b) nanoparticles deposited on copper TEM grid.

The synthetic procedure of $\mathrm{Pt}_{0.5} \mathrm{Pd}_{0.5}$ nanoparticles is similar to that used for the $\mathrm{Rh}_{0.5} \mathrm{Pd}_{0.5}$ nanoparticles, except that $0.05 \mathrm{mmol} \mathrm{Pt}(\mathrm{acac})_{2}$ and $0.05 \mathrm{mmol} \mathrm{Pd}(\mathrm{acac})_{2}$ were added to $20 \mathrm{ml}$ of 1,4-butanediol in a $50 \mathrm{ml}$ three-necked flask at room temperature followed by reaction at $215^{\circ} \mathrm{C}$ for $0.5 \mathrm{~h}$.

The shape and size of the bimetallic nanoparticles were analyzed by transmission electron microscopy (TEM). Representative images of $\mathrm{Rh}_{0.5} \mathrm{Pd}_{0.5}$ and $\mathrm{Pt}_{0.5} \mathrm{Pd}_{0.5}$ nanoparticles are shown in Figs. S2a and S2b, respectively.

Monolayers of the bimetallic nanoparticles on silicon wafers were prepared by placing drops of the nanoparticle chloroform solution onto the water subphase of a LB trough (Nima Technology, M611) at room temperature. The resulting surface layer was compressed to form a dense monolayer and transferred onto a silicon wafer using the Langmuir-Schäffer horizontal lift-off method. Monolayers of bimetallic nanoparticles prepared in this manner were found to be relatively homogeneously distributed on the silicon wafers and were used for reaction studies.

\section{Core-shell Structure of the $\mathbf{R h}_{0.5} \mathbf{P d}_{0.5}$ and $\mathbf{P t}_{0.5} \mathbf{P d}_{0.5}$ Nanoparticles}

The $\mathrm{Rh}_{0.5} \mathrm{Pd}_{0.5}$ and $\mathrm{Pt}_{0.5} \mathrm{Pd}_{0.5}$ nanoparticles have a core-shell structure, as shown by the changes in the XPS peak intensities of the component atoms as a function of $\mathrm{x}$-ray energy. The key result of this work is the discovery of the changes in the atomic distribution in the shell and core from the initial as-synthesized condition to that under reaction conditions. To analyze the results quantitatively we take advantage of the variable energy of $\mathrm{x}$-rays in the Synchrotron. These energies were chosen such that all photoelectrons of the $\mathrm{Rh}, \mathrm{Pd}$ and $\mathrm{Pt}$ atoms had the same three values of their kinetic energy equal to approximately 350,540 and $1180 \mathrm{eV}$. The mean free paths corresponding to these kinetic energies are $0.7,1.0$ and $1.6 \mathrm{~nm}$, as described in the main text. These distances provide a natural way to define three depths of the nanoparticle explored by XPS, which we label as shell, intermediate and core. The volume of material analyzed within these three depths is $25 \%, 35 \%$ and $51 \%$ respectively.

These regions are not to be understood as exact and well delineated by spheres. The mean free path is simply the average distance traveled by the electrons of a given energy, and is defined as the distance where the probability of escape has decayed to $1 / \mathrm{e}$ or $37 \%$. 
4. Determination of the atomic fractions of Rhodium, Palladium and Platinum in the Nanoparticles

The number of rhodium or palladium atoms within the detection region was obtained from the $\mathrm{Rh} 3 \mathrm{~d}$ or $\mathrm{Pd} 3 \mathrm{~d}$ peak areas. The areas were then normalized by the atomic ionization cross sections at the corresponding X-ray energies, as tabulated in reference 3 . The atomic fraction of a given atom is obtained by dividing the number atoms by the total number of metal atoms.

5. Evolution of $R h$ and $P d$ Atomic Fractions of $R_{h_{0.5}} P d_{0.5}$ in Sequential Reducing, Catalytic, and Oxidizing Conditions

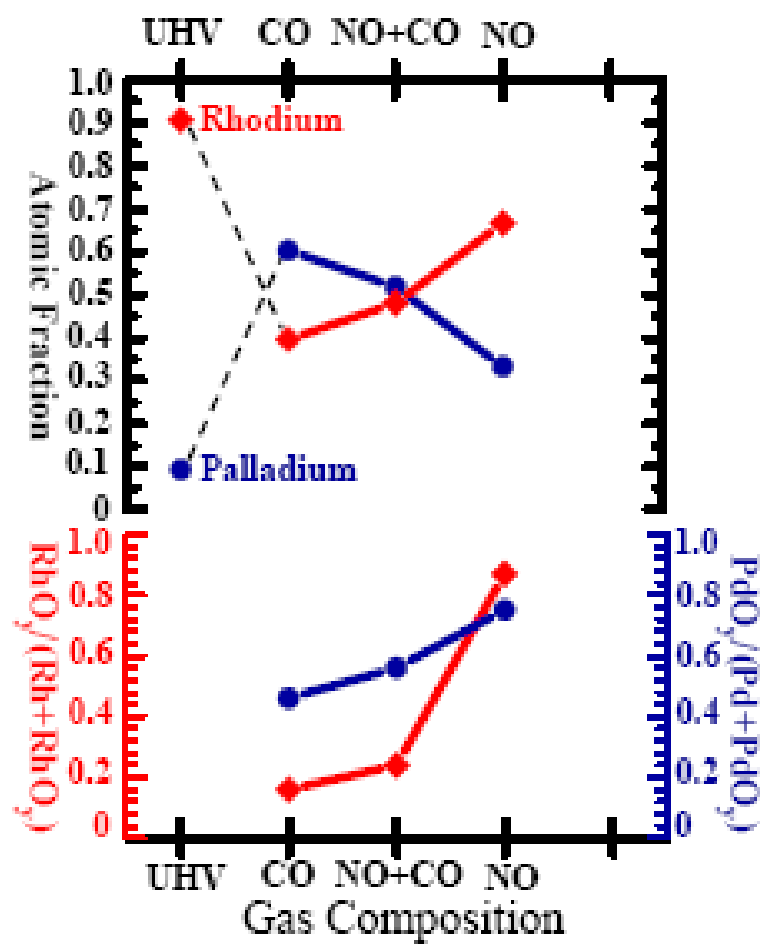

Fig. S3. Top panel: evolution of rhodium $\left(\mathrm{Rh}^{0}+\mathrm{Rh}^{2 \mathrm{y}+}\right)$ and palladium $\left(\mathrm{Pd}^{0}+\mathrm{Pd}^{2 \mathrm{y}+}\right)$ atomic fractions of $\mathrm{Rh}_{0.5} \mathrm{Pd}_{0.5}$ nanoparticles at $300^{\circ} \mathrm{C}$ under reducing conditions (100 mTorr CO), under catalytic conditions (100 mTorr CO and 100 mTorr NO), and under oxidizing conditions (100 mTorr NO), as indicated in the X-axis. The bottom panel shows the evolution of the atomic fraction of the oxidized $\mathrm{Rh}$ (or Pd) atoms in the total rhodium (or palladium) atoms of the shell under the same reaction conditions as the top panel. All atomic fractions were obtained at an X-ray photon energy of $645 \mathrm{eV}$ $(\mathrm{KE}=\sim 310$ and $\sim 335 \mathrm{eV})$.

6. Evolution of $\mathrm{Rh}$ and $\mathrm{Pd}$ Atomic Fractions of $\mathbf{R h}_{0.5} \mathbf{P d}_{0.5}$ in Alternating Oxidizing (NO) and Reducing $\left(\mathrm{H}_{2}\right)$ Conditions 


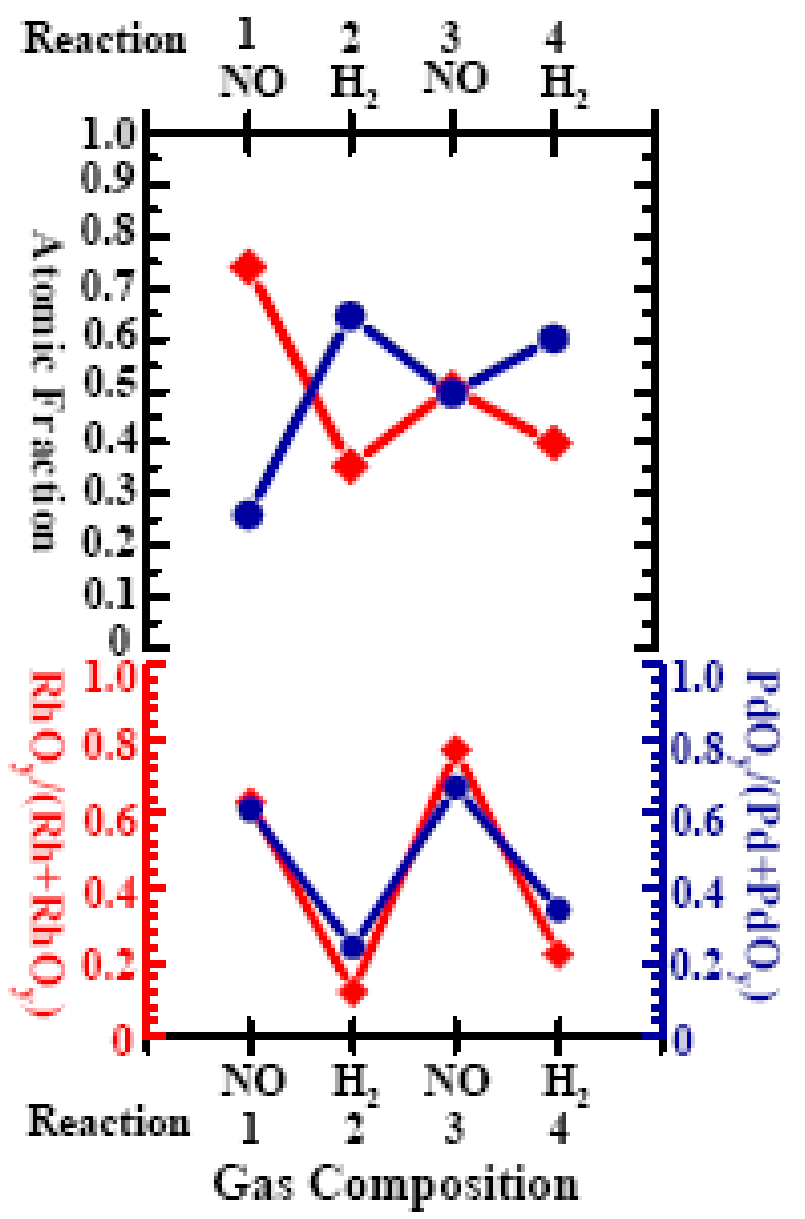

Fig. S4. Top panel: evolution of atomic fractions of rhodium $\left(\mathrm{Rh}^{0}+\mathrm{Rh}^{2 \mathrm{y}+}\right)$ and Palladium $\left(\mathrm{Pd}^{0}+\mathrm{Pd}^{2 \mathrm{y}+}\right)$ in $\mathrm{Rh}_{0.5} \mathrm{Pd}_{0.5}$ nanoparticles at $200^{\circ} \mathrm{C}$ under oxidizing (100 mTorr NO) and reducing conditions (100 $\mathrm{mTorr}_{2}$ ), as noted in the X-axis. Bottom panel: evolution of the atomic fraction of the oxidized $\mathrm{Rh}$ (or oxidized $\mathrm{Pd}$ ) atoms relative to the total number of rhodium (or palladium) atoms of the shell under the same reaction conditions as the top panel. All atomic fractions were obtained at an Xray photon energy of $645 \mathrm{eV}(\mathrm{KE}=\sim 310$ and $\sim 335 \mathrm{eV})$.

\section{References of Supporting on-line Material}

1. D. F. Ogletree, H. Bluhm, G. ebedev, C. S. Fadley, Z. Hussain, M. Salmeron, Review of Scientific Instruments 73, 3872 (2002).

2. M. Salmeron, R. Schlogl, Surface Science Reports 63, 169 (2008).

3. J. J. Yeh, I. L. Lindau, Atomic Data and Nuclear Data Tables 32, 1 (1985). 